\title{
Research on Empirical Visualization of Counter-Terrorism Based on UCINET
}

\author{
Ling-Zhi Jiang \\ Department of Information Engineering, Engineering \\ University of CAPF, Xi'an, 710086, China \\ Email: flyhigherest@163.com,

\section{Li-Tao Qiao} \\ Battalion of Communicate, 8670 Troop of CAPF, \\ Pingliang, 744000, China \\ Email: bookforc@163.com
}

\begin{abstract}
With the terrorist organization develops in the form of network, this paper applies social network analysis method to analyze the relationship between the social network of the networking terrorist organization so as to reveal the involving relationship of terrorist activities between leaders and members of the terrorist organization, thus to help prevent and combat terrorism. Network visualization analysis tools UCINET possesses powerful function of data visualization and dynamic data analysis. In this paper, we first describe the steps of counter-terrorism analysis based on social network analysis and UCINET. Finally, by using "3.01" event in Kunming as an example and employing UCINET software to make a visual empirical research on counter-terrorism network, we analyze the network density and central measure value.
\end{abstract}

Keywords- UCINET; social network analysis; terrorist organization; anti-terrorism; demonstration

\section{INTRODUCTION}

For a long time, terrorism has been making chaos in many parts of the world with its bloody violence, cause social unrest. With the deepening of the global anti-terrorism, the structure of the terrorist organization has changed a great change. Network organizational structure is gradually replacing the hierarchical organizational structure, which has become an important support for the survival and the destruction of the terrorists [1]. Social network analysis method is an approach used to make quantitative analysis on various relations in social network and network structure [2]. For the premeditated terrorist activities and with application of social network analysis theory, this paper uses dots to represent terrorists and all kinds of crime and analyzes the relationship between the dots with network analysis tools UCINET so as to work out visualized relations network charts and quantitative data. For example the network density and centrality measurement equivalent data worked out could provide a useful reference for making counter-terrorism policy [3].

In this paper, we first describe the steps of Counter-Terrorism Analysis Based on social network analysis and UCINET, Finally, by using "3.01" event in Kunming as an example and employing UCINET software

\author{
Qi-Wu Wu* \\ Email: wuqiwu700@163.com
}

to make a visual empirical research on counter-terrorism network, we analyze the network density and central measure value.

\section{II.THE ANALYSIS STEPS OF \\ COUNTER-TERRORISM BASED ON SOCIAL NETWORK ANALYSIS AND UCINET}

Using intelligence reconnaissance and search technology to achieve counter-terrorism intelligence, to provide data support for the establishment of a network model based on social network analysis.

Using the theory of six degree space to analyze the elements of terrorism. For example, to find out the relationship between the known terrorists, and then to analyze the relationship between the known terrorists, to find their relationship, in order to continue to expand, until all the members to find.

This paper employs the rows or columns of the relation matrix to represent terrorists and those related skills, resources, tasks, location and other factors and uses the related value to indicate the tightness relation between the terrorists and the various elements.

The terrorist relation matrix is introduced into the social network analysis software UCINET to establish the network model of the terrorist organization.

After the measurement and calculation of the network of terrorist organizations, using UCINET and other software to study the characteristics of the network of terrorist organizations, commonly used analysis indicators are density, centrality, structural equivalence, etc.. For example, density is a common indicator of the aggregation of members in the network, defined as the proportion of the total number of actual connections between the members and the maximum possible number of connections. Higher density indicates the members are more closely, the resources and information are delivered faster and the action efficiency is higher, but also it is more likely to be exposed. Conversely, better hidden, lower action efficiency..

\section{EMPIRICAL RESEARCH ON “ $3 \bullet 01$ ” EVENT IN KUNMING BASED ON UCINET}

Collect intelligence information. By searching on the Internet, the basic information about Kunming "3.01" event was as follows [4]: At 21:20 on March 1, 2014, a serious 
violent terrorist incident took place in Kunming Railway Station, Yunnan Province. The incident was planned and organized by Xinjiang separatists led by Abudureyimu Kuerban. The gang includes 8 persons (6 men and 2 women). On the evening of March 1, 2014, because of out of touch with Eptastigmine Kendall Ai Haiti and other people, Abdul Geim kuerban, Akomati A Beatti, Patiguli Tuoheti, ArMia Tursun and Mangshar Shamil negotiated to committed violent and terrorist activities at Kunming Railway Station. Therefore, the five persons rent a car from Shadian to the destination, carrying with tools of crime. At $21: 12$, they carried sabers to indiscriminately stab innocent people in the name of terrorism from Front Square, No.2 Ticketing Area, Ticketing Area to Small Package Storage, which caused 31 deaths and 141 injuries. Thereof, 4o people were seriously injured. Due to their resistance arrest, expect Patiguli Tuoheti who was shot and arrested by the police, the remaining four were shot to death on site. On March 2, thanks to the police's efforts to carpet arresting of the escaped Kunming "3.01" event terrorists, three criminals were arrested at Shangyi Street in Kunming. The scene evidences of Kunming " 3.01 " event prove that this is a serious violent terrorist event planned and organized by Xinjiang separatists.

Establish terrorist relation matrix. Viewed from causes and process of " 3.01 " event, it can be divided into two stages: organization \& planning stage and action implementation stage. In the second stage, the number of participants is relatively large. Members are complex. Therefore, it is very difficult to collect and determine the information of participants. The main process of "3.01" event planning and organizing includes discovering available information, distorting facts and spreading rumors. According to the process, this paper makes conclusion from the page text information and confirms four basic elements. First, the planning \& organization terrorist are expressed as A. Second, the skills required are expressed as K. Third, the background events of case are expressed as B. Fourth, the specific task are expressed as T. the basic relationship between the elements of the event as shown in table 1 .

TABLE 1 RELATION DIAGRAM OF EVENT ELEMENT

\begin{tabular}{|c|c|c|c|c|}
\hline number & character & task & skill & event \\
\hline A01 & Abdul Geim kuerban & T2, T3, T4, T5 & K1, K2, K3, K4 & B03 \\
\hline A02 & Akomati A Beatti & T3, T4, T5 & K3 & B03 \\
\hline A03 & Patiguli Tuoheti & T3, T4, T5 & K3 & B03 \\
\hline A04 & A1 MIA - tursun & T3, T4, T5 & K3 & B03 \\
\hline A05 & Blind - Shamil. & T3, T4, T5 & K3 & K2 \\
\hline A06 & Eptastigmine Kendall Ai Haiti & T1, T2 & B03 \\
\hline A07 & Spit Khun - Tropsch niyazi & T3 & B01,B02 \\
\hline A08 & Yushan Maimaiti & T3 & K1, K2 & B01 \\
\hline A09 & Xinjiang independence violence terrorist organization contact & T2 & K1 \\
\hline A10 & Foreign terrorist organizations contact violence & T1 &
\end{tabular}

Utilize software to establish terrorist network model. Relation matrix data (in excel) is led into UCINET software. Visual tool NetDraw in UCINET is used to draw the relation between terrorist and terrorist (Figure 1), the relation between terrorist and task (Figure 2), the relation between task and task (Figure 3 ) and the relation between task and skill (Figure 4).

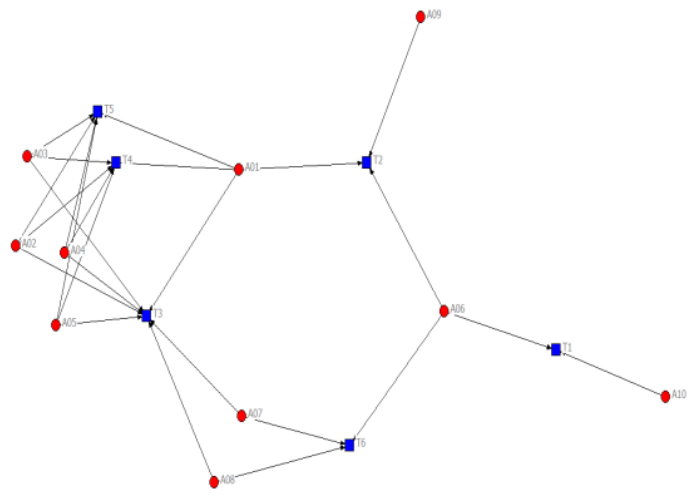

Figure.1. Terrorist-task relation

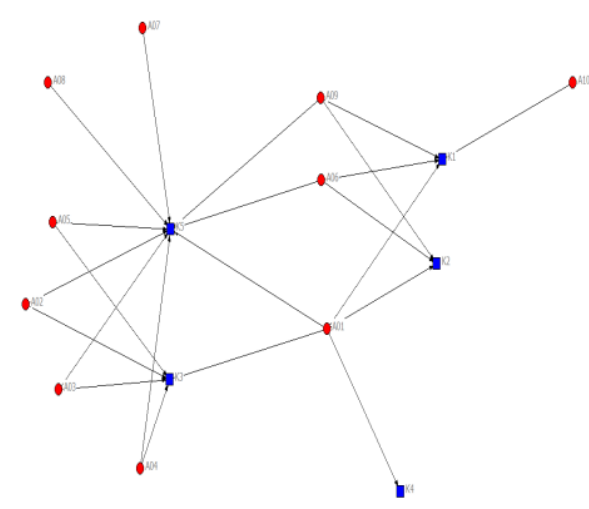

Figure.2. Terrorist-skill relation 


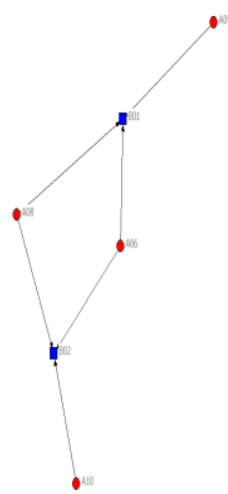

Figure.3.

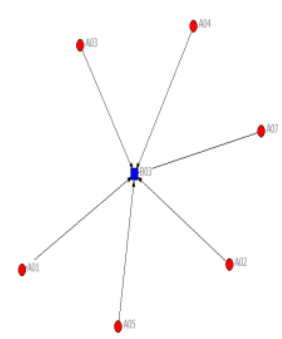

Task-task relation

Analyze terrorist concealed network. Figure 5 for the terrorist-terrorist relationship matrix, Figure 6 shows terrorist-terrorist relation network density and centrality indexes measured with UCINET software. As shown in Figure 6.It can be seen the density of terrorist-terrorist relation network is 1 . The Value states that there are contacts among terrorists involving in " $3 \cdot 01$ " terrorist attacks, so all the terrorists should be caught through tracking the terrorists following the clues when fighting against the terrorists. As shown in Figure 6, terrorists with point centrality and intermediary centrality ranked the top one is A01 (Aihemaiti Tursun), indicating that he is of great importance in the relation network. Viewed from actual situation of the event, the terrorists is principal planners of "3.01" event. According to the same method, we can get valuable information from other network graph. For example, if greater centrality was found in task T3 when measuring and calculating the centrality through the task relationship network diagram, it indicates that this task is of great importance in the whole violent terrorist event.

12345678910

$\mathrm{A} A \mathrm{AAAAAA}$

- - . - . . - -

A01 $4 \begin{array}{lllllllllllll} & 3 & 3 & 3 & 3 & 1 & 1 & 1 & 1 & 0\end{array}$

$\mathrm{A} 02 \quad 3 \quad 3 \quad 3 \quad 3 \quad 30011100$

$\mathrm{A} 03 \quad 3 \quad 3 \quad 3 \quad 3 \quad 30011100$

A04 30333333011100

$\mathrm{A} 05 \quad 3 \quad 3 \quad 3 \quad 3 \quad 30011100$

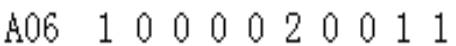

A07 111111110011100

A08 111111110011100

A09 1100000110010

A10 0000000110001

Figure.5. Terrorist-terrorist relationship matrix

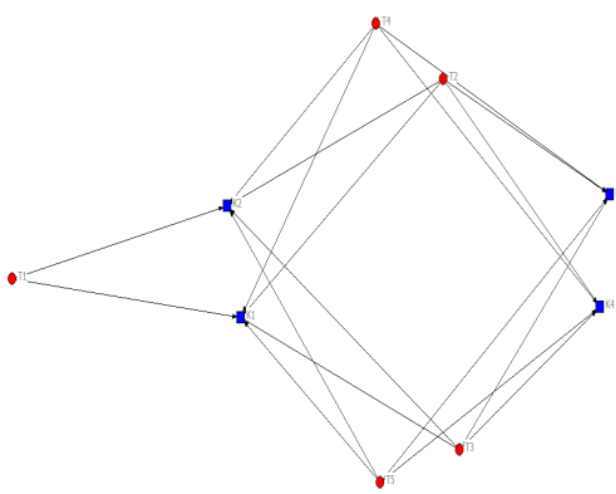

Figure.4. Task-skill relation

Relation: 1

Density (matrix average) $=1.0000$

Standard deviation $=1.1547$

$\begin{array}{rrrr} & \begin{array}{r}1 \\ \text { Degree }\end{array} & \begin{array}{r}2 \\ \text { NrmDegree }\end{array} & \begin{array}{r}3 \\ \text { Share }\end{array} \\ \text { 1 A01 } & 16.000 & 59.259 & 0.178 \\ \text { 2 A02 } & 14.000 & 51.852 & 0.156 \\ \text { 3 A03 } & 14.000 & 51.852 & 0.156 \\ \text { 4 A04 } & 14.000 & 51.852 & 0.156 \\ \text { 5 A05 } & 14.000 & 51.852 & 0.156 \\ \text { 8 A08 } & 6.000 & 22.222 & 0.067 \\ \text { 7 A07 } & 6.000 & 22.222 & 0.067 \\ \text { 6 A06 } & 3.000 & 11.111 & 0.033 \\ 9 \mathrm{A09} & 2.000 & 7.407 & 0.022 \\ 10 \mathrm{~A} 10 & 1.000 & 3.704 & 0.011\end{array}$

Figure.6. Measurements of the density and the centrality

\section{CONCLUSION}

At the present, with the deepening global action against terrorism in the countries around the world, the structure of the terrorist organizations gradually turns to be a more subtle, flat network structure from a single, top-down pyramid one. The research method of terrorism theory based on the social network analysis theory will become the mainstream research method and the inevitable trend for terrorist organizations research. However, the method of constructing the relation matrix needs to be further studied. For example, hyper-graph can be used to describe the relations among different elements in terrorist activities.

\section{ACKNOWLEDGEMENT}

This work is supported by the National Science Foundation Project of P. R. China (No.61402529); the Natural Science Basic Research Plan in Shanxi Province of China (No.2015JQ6266); the Basic Research Foundation of Armed Police Engineering University (No.WJY201417, No.XJY201403); the Military Theory Research Foundation of Armed Police Engineering University (No.JLX201645).

\section{REFERENCES}

[1] R. M. Adler. A Dynamic Social Network Software Platform for Counter-Terrorism Decision Support. IEEE Intelligence and Security Informatics, 23 (2007) 47-54. 
[2] Zheng Zhihao. Application of Social Network Analysis Method in Counter-terrorism", Journal of Chinese People's Public Security University, 7 (2012) 11-13.

[3] Zhang Hai. Research on Terrorist Organization Concealed Network based on Social Network Theory, Hunan: National University of
Defense Technology, 2010.

[4] Zhao Bingzhi, Shang Haowen, to promote the rule of law in criminal cases, the rule of law - in 2014 the ten typical cases of criminal cases [J]. People's police, 2015, (2):35-40. 